\title{
Effects of hypoxia on early life history of the stomatopod Oratosquilla oratoria in a coastal sea
}

\author{
Keita Kodama $^{1,5, *}$, Toshihiro Horiguchi ${ }^{1,5}$, Gen Kume ${ }^{1,6}$, Satoshi Nagayama ${ }^{2}$, \\ Takamichi Shimizu ${ }^{3}$, Hiroaki Shiraishi ${ }^{1,5}$, Masatoshi Morita ${ }^{1}$, Makoto Shimizu ${ }^{4}$
}

${ }^{1}$ Endocrine Disrupters and Dioxin Research Project, National Institute for Environmental Studies, 16-2 Onogawa, Tsukuba, Ibaraki 305-8506, Japan

${ }^{2}$ Agriculture, Forestry and Fisheries Department, Chiba Prefectural Office, 1-1 Ichibacho, Chuou-ku, Chiba, Chiba 260-8667, Japan

${ }^{3}$ Resources and Environment Division, Kanagawa Prefectural Fisheries Technology Center, Jogashima, Misaki, Miura, Kanagawa 238-0237, Japan

${ }^{4}$ Faculty of Agriculture, University of Tokyo, 1-1-1 Yayoi, Bunkyo, Tokyo 113-8657, Japan

${ }^{5}$ Present address: Research Center for Environmental Risk, National Institute for Environmental Studies, 16-2 Onogawa, Tsukuba, Ibaraki 305-8506, Japan

${ }^{6}$ Present address: Faculty of Fisheries, Nagasaki University, Bunkyo-machi, Nagasaki 852-8521, Japan

\begin{abstract}
Bottom hypoxia is considered to be one of the factors affecting the recent stock decline of the mantis shrimp Oratosquilla oratoria in Tokyo Bay, Japan. We used field surveys of the bay to investigate the spatiotemporal pattern of bottom hypoxia and the early life history of $O$. oratoria, and we examined the effects of bottom hypoxia on early life history by nonparametric analyses. Bottom hypoxia in Tokyo Bay began to appear in April, occupied more than half (55 to $67 \%$ ) of the whole bay area in July and August, and disappeared from November onward. Newly settled juveniles appeared in September-October in the northeastern shallow coastal area, where the hypoxic bottom water had disappeared. After the hypoxia had abated, the distribution of juveniles expanded to the southcentral deep area. Classification and regression tree analysis showed that the threshold level of bottom dissolved oxygen concentration for the existence of juveniles was $2.78 \mathrm{ml} \mathrm{l}^{-1}$, implying that hypoxia restricted the spatial distribution of juveniles. A generalized additive model showed that sampling date, bottom dissolved oxygen concentration, depth, latitude, and longitude had significant effects on the occurrence of juveniles, suggesting an adverse effect of hypoxia on the time and location of settlement of $O$. oratoria. Our results suggest that hypoxia is directly and/or indirectly associated with mass-mortality events during early life history.
\end{abstract}

KEY WORDS: Hypoxia $\cdot$ Settlement $\cdot$ Recruitment $\cdot$ Juvenile $\cdot$ Oratosquilla oratoria $\cdot$ Tokyo Bay

\section{INTRODUCTION}

Oxygen depletion (hypoxia) in bottom water occurs in eutrophic estuarine and coastal systems throughout the world and is a growing global problem (Diaz \& Rosenberg 1995). Bottom hypoxia (dissolved oxygen [DO] concentration $\leq 2 \mathrm{ml} \mathrm{l}^{-1}$; Diaz \& Rosenberg 1995) has various adverse effects on benthic organisms. For example, hypoxia induces mass mortality of sessile benthic organisms (Baden et al. 1990). Motile animals (e.g. fishes, crabs, or shrimps) can avoid hypoxic areas and migrate to normoxic refuges (e.g. Pihl et al. 1991, Breitburg 1992, Eby \& Crowder 2002, Craig \& Crowder 2005). This migration, however, causes contraction of the spatial distribution of motile fishes and invertebrates to oxygenated areas, which results in higher densities and substantial overlap with competitors and predators, suggesting the possibilities of higher risks of predation, increased competition for limited prey availability, and subsequent decrease in growth rate 
(e.g. Baden et al. 1990, Eby \& Crowder 2002, Craig \& Crowder 2005, Eby et al. 2005). In addition, hypoxia impairs fish reproduction; exposure of adults of the carp Cyprinus carpio to hypoxic water in a laboratory experiment caused a decrease in serum levels of testosterone, estradiol, and triiodothyronine, and this in turn resulted in deterioration of gonadal development, spawning success, fertilization success, hatching rate, and larval survival (Wu et al. 2003).

Tokyo Bay, central Japan (see Fig. 1), is a heavily eutrophic area in which hypoxia occurs in the bottom water from spring to autumn (Fujiwara \& Yamada 2002). The mantis shrimp Oratosquilla oratoria (Crustacea: Stomatopoda), is one of the dominant species in the demersal fauna of Tokyo Bay, and it is the most commercially valuable species in the bottom-trawl fisheries there (Kodama et al. 2002, 2003, 2006b). However, the stock size of $O$. oratoria in Tokyo Bay dropped dramatically in the late 1980s and has since remained low (Kodama et al. 2002), resulting in hardship for the local fishing industry. From multivariate analyses of long-term biotic and abiotic data, Kodama et al. (2002) hypothesized that a decreasing trend in dissolved oxygen concentration in the bottom water of the bay may be one of the factors causing the stock-size decline of $O$. oratoria and other benthic organisms there, although the mechanisms have remained unclear.

In marine organisms, survival during the early life stages (egg, larval, and juvenile stages) is considered the most important phase determining subsequent year-class strength, through the effect of predation, starvation, and physical processes such as passive transportation during the egg and/or larval stages (Jennings et al. 2001). Hypoxia is also a factor affecting survival of the early life stages of aquatic organisms. Experimental studies have shown that predation of naked goby Gobiosoma bosc larvae by scyphomedusa Chrysaora quinquecirrha increases in hypoxic conditions, probably as a result of impairment of the ability of the larvae to escape the scyphomedusa (Breitburg et al. 1994, 1997). Few field studies have shown the effects of hypoxia on postsettled juveniles in field situations. In Chesapeake Bay, intrusion of the most severely hypoxic water into the areas where recruitment of postsettled G. bosc is highest coincides with the peak periods of recruitment. This results in extremely high mortality of the newly settled juveniles, which require higher dissolved oxygen concentrations than do older individuals (Breitburg 1992). In the Neuse River Estuary, the growth rate of juveniles of the Atlantic croaker Micropogonias undulatus is declining with habitat contraction and decreased prey availability, which have resulted from the effects of hypoxia; this will probably also result in a reduction in population growth rate (Eby et al. 2005).
An understanding of the early life history of Oratosquilla oratoria and the factors affecting mortality during each life stage is critical if we are to understand the mechanisms that determine the year-class strength. We aimed to reveal the effects of hypoxia on the early life history of $O$. oratoria - in particular on the time and location of settlement and the spatial distribution of juveniles. We collected hydrographic data and $O$. oratoria juveniles by baywide field sampling and used nonparametric analyses to investigate: (1) the temporal pattern of the spatial extent and distribution of hypoxia in the bay; (2) the spatiotemporal pattern of the occurrence of juveniles in the bay; and (3) the effect of hypoxia on the early life history of $O$. oratoria.

\section{MATERIALS AND METHODS}

General life history traits of Oratosquilla oratoria. In Tokyo Bay, $O$. oratoria lives for at least $4 \mathrm{yr}$ (Kodama et al. 2005, 2006c). Its spawning season lasts from April to September. There are 2 spawning peaks for the population in Tokyo Bay: the early spawning season in May by large females of body length (BL) $\geq$ $10 \mathrm{~cm}(\geq 1 \mathrm{yr})$ and the late spawning season in August by small females of $7 \leq \mathrm{BL}<10 \mathrm{~cm}(0-1 \mathrm{yr}$ Kodama et al. 2004, 2006a) (BL is measured from the base of the rostrum to the anterior edge of the median notch of the telson). The spawning ground of $O$. oratoria is located in the southern part of the bay (below the line between the Tama River and Sodegaura; Ohtomi \& Shimizu 1991; see Fig. 1). After spawning females brood their eggs for 2 to $3 \mathrm{wk}$ until hatching, and the larval phase lasts 5 to $7 \mathrm{wk}$ (Hamano \& Matsuura 1984, 1987a). Therefore, it takes 7 to $10 \mathrm{wk}$ from egg laying to settlement.

Hydrographic data. To assess the effects of hypoxia on the early life history of Oratosquilla oratoria, we examined the temporal and spatial distribution and spatial extent of hypoxic bottom water. Contour maps of the DO concentrations in the bottom layer $(<1 \mathrm{~m}$ above the sea bottom) of Tokyo Bay from April to December 2004 were obtained from the website of the Chiba Prefectural Fisheries Research Center (www.pref. chiba.jp/laboratory/fisheries/index; in Japanese), from which 1 to 4 DO contour maps were available each month. The DO contours were generated using the computer software Program for Displaying Water Qualities of Tokyo Bay (Chuden CTI, Nagoya, Japan) with a spline interpolation routine. To quantify the spatial extent of hypoxia, the proportion of hypoxic (DO $\leq 2 \mathrm{ml} \mathrm{l}^{-1}$ ) area was calculated for each contour map by dividing the number of pixels of hypoxic area by the total number of pixels in the study area and multiplying by 100, using Adobe Photoshop 5.5 image processing software. 
During juvenile sampling (see next section), we also observed water temperature and salinity in the surface $(<1 \mathrm{~m}$ below the sea surface) and bottom $(<1 \mathrm{~m}$ above the sea bottom) layers and DO concentration in the bottom layer, using a YSI-85 conductivity, temperature, and depth (CTD) probe (YSI Inc.). The monthly averages for each hydrographic variable at the surface and bottom of the study area were calculated. The differences in the monthly mean temperature $(\Delta T)$ and salinity $(\Delta S)$ between the surface and bottom were calculated for each month to examine the formation of stratification in the bay.

Juvenile data. To reveal the timing and location of settlement as well as their spatial distribution, juvenile Oratosquilla oratoria were collected by bottom-trawl surveys from June to December 2004. Data on the spawning period and the length of time between spawning and larval settlement (Hamano \& Matsuura 1987a, Kodama et al. 2004, 2006a) had indicated that juveniles could be present in the bay at this time. The bottom-trawl surveys were conducted monthly at 25 stations throughout the bay from June to August 2004 and at 22 stations from September to December 2004 (Fig. 1) by the trawlers 'Hokuei-maru' and 'Naneimaru'; both trawlers were supplied by the Council of Inner Bay Trawl Fisheries of Chiba Prefecture. A dredge trawl (cod-end mesh size $1.8 \mathrm{~cm}$, net mouth $0.4 \mathrm{~m}$ high by $1.2 \mathrm{~m}$ wide) was used for sampling. The towing speed was 2 to 4 knots, and the towing duration was adjusted to between 10 and $150 \mathrm{~s}$ to avoid damage to the net from large amounts of bycatch, such as mud, litter, and organisms other than $O$. oratoria. The towing distance (m) was recorded at each station. Young-of-the-year juveniles do not reach more than $8 \mathrm{~cm}$ BL until the end of the year, and it is easy to distinguish them from larger individuals $>1$ yr old (Kodama et al. 2005). Therefore, we defined individuals of $<8 \mathrm{~cm}$ BL as young-of-the-year juveniles. The number of juveniles divided by the towed area (towed distance $x$ net width) was calculated for each station as an abundance index of juveniles (individuals $\mathrm{m}^{-2}$ ).

Data analysis. To reveal the threshold DO concentration for the presence or absence of juveniles, we conducted a classification and regression tree (CART) analysis, a nonparametric stepwise splitting approach whereby a dataset is progressively split into sub- sets that most significantly reduce the variability of the response variable (Clark \& Pregibon 1992, Eby \& Crowder 2002), using the juvenile presence/absence data and the DO concentration.

To elucidate the spatiotemporal effect of abiotic variables on the spatial distribution and settlement period of juveniles, we used a generalized additive model (GAM). A GAM is a nonparametric extension of the generalized linear model. In the GAM, the explanatory variables are related to the response variable by a linear and/or nonlinear smoothing function and the data are subjected to less restrictive distributional assumptions than in linear regression (Hastie \& Tibshirani 1990, Hastie 1992). In our GAM analysis we used hydrographic variables of the bottom layer (water temperature, salinity, and DO concentration), geographic variables (depth, latitude, and longitude), and a temporal variable (sampling date as the number of days since 1 January 2004) at each station as explanatory variables, and the presence or absence data on juveniles as the response variable. All explanatory variables were numeric. We assumed a binomial distribution for the GAM model (chi-squared goodness-of-fit test, $\mathrm{p}>0.05$ ). To remove the explanatory variables that did not contribute to the model, a backward

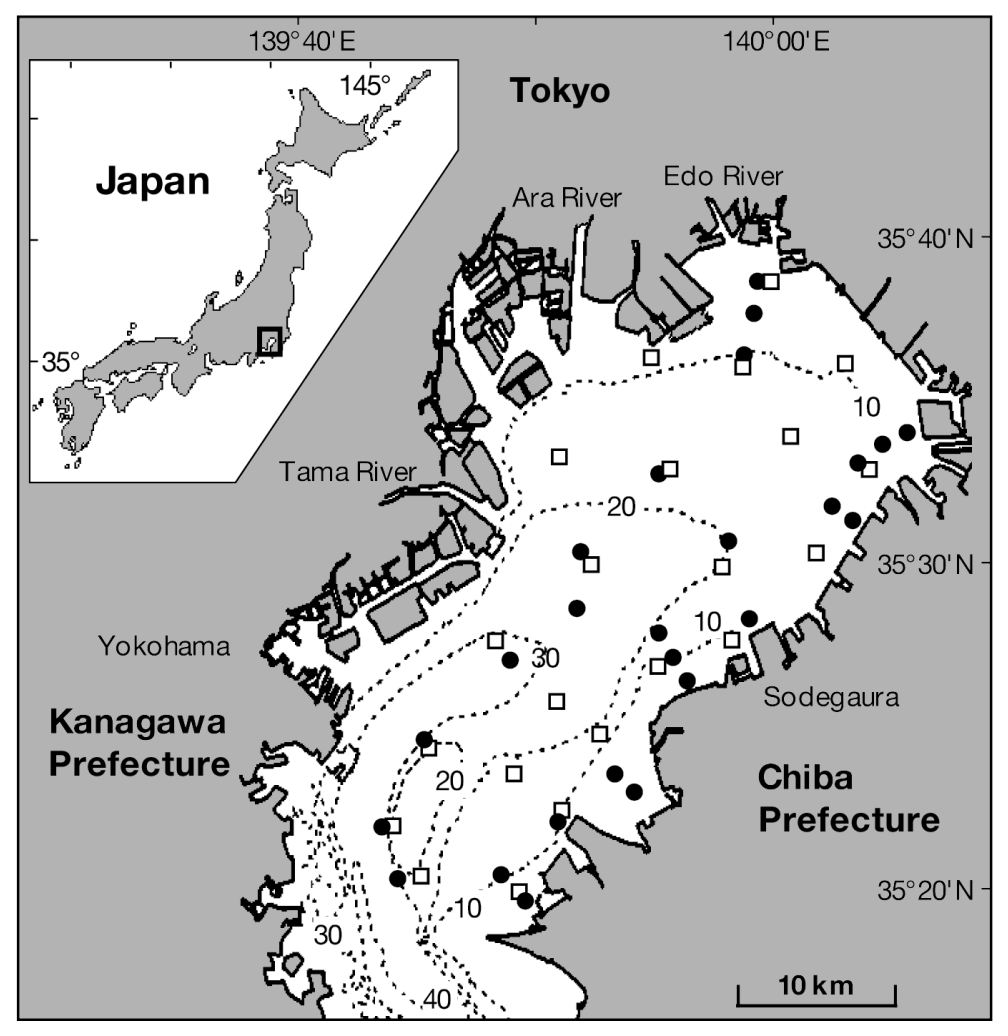

Fig. 1. Locations of bottom trawl surveys of Tokyo Bay, Japan. Sampling was

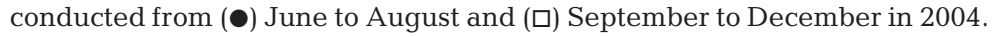
Dotted lines: depth contours (m) 
stepwise elimination procedure was carried out (Hastie \& Tibshirani 1990, Hastie 1992). We allowed each explanatory variable to enter or be excluded from the model as a linear or nonlinear smoothing function, and we accepted the model with the minimum Akaike's information criterion (AIC) as the optimum model (Akaike 1973, Hastie \& Tibshirani 1990, Hastie 1992). The pseudo- $\mathrm{R}^{2}$ of the optimum model was calculated (Swartzman et al. 1992). The significance of each explanatory variable in the model was tested by the approximate F-test (Hastie \& Tibshirani 1990). All statistical analyses were performed with the computer software S-plus 2000 (Mathsoft).

\section{RESULTS}

\section{Seasonal changes in hydrographic variables}

Water temperature showed a clear seasonal trend: it increased from April, peaked in August, and declined from September onward (Fig. 2a). Positive values of $\Delta T$ occurred from April to September, suggesting formation of a thermocline in the bay.

Salinity variables did not show a clear seasonal trend, except for a decline in surface salinity in October (Fig. 2b). Surface water was fresher than the bottom water from April to November, during which time $\Delta S$ ranged from -9.0 to -1.3 psu (Fig. $2 b$ ).

Monthly mean DO concentration dropped between June and September, ranging from 2.4 to $3.1 \mathrm{ml} \mathrm{l}^{-1}$ (Fig. 2c). The spatial extent and distribution of hypoxia in the bay fluctuated throughout the survey period. Hypoxic bottom water (DO $\leq 2 \mathrm{ml} \mathrm{l}^{-1}$ ) was continually present in the bay from April to October, although it temporarily abated on 24 June and 1 September (Fig. 3). The hypoxic area in the bay increased from May onward, and occupied more than half (55 to $67 \%$ ) of the whole bay area in July and August (Fig. 2c). Hypoxia abated after August, and no hypoxia was recorded from November onward (Figs. 2c \& 3). Hypoxia was found mainly in the north-central part of the bay, but it expanded toward the southern part of the bay from late July to late August.

\section{Effects of hypoxia on early life history}

No juveniles occurred until September (Fig. 3). Juveniles were not found in hypoxic areas with DO $\leq$ $2 \mathrm{ml} \mathrm{l}^{-1}$ (Fig. 3, see also Fig. 4). In October the hypoxia began to abate, and juveniles increased in abundance and settled in the shallow eastern coast of the bay, where there was no severely hypoxic water (Fig. 3). The highest juvenile abundance was
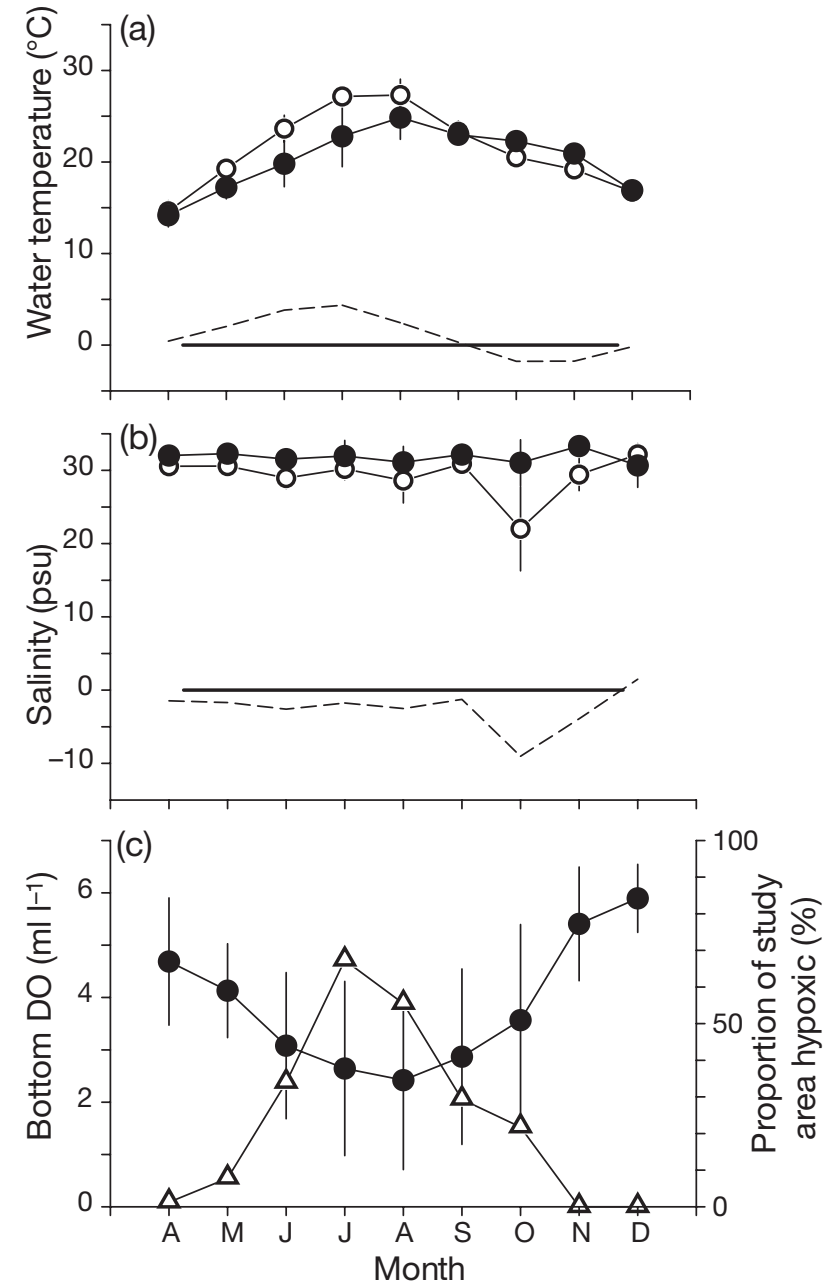

Fig. 2. Monthly changes in mean (a) surface and bottom temperature and $\Delta T$ (broken line), (b) surface and bottom salinity and $\Delta S$ (broken line), and (c) bottom DO concentration (left axis) and the proportion of study area with hypoxic bottom water (DO $\leq 2 \mathrm{ml} \mathrm{l}^{-1}$; right axis) between April and December 2004. (O) Surface layer data; ( ) bottom layer data; $(\Delta) \%$ sample area hypoxic; vertical bars: SE

found off the northeastern coast of the bay from October to December. The distribution of juveniles expanded from the northeastern shallow area to the south-central deep area from November onward, during which the hypoxic area disappeared from the bay (Fig. 3). This expansion was probably the result of migration from the northeastern settlement ground rather than new settlement, because newly settled juveniles $(2 \leq \mathrm{BL}<3 \mathrm{~cm})$ were found only from September to October.

To reveal the effects of hypoxia on the spatial distribution of juveniles, we conducted CART analyses between September and December, during which period juveniles occurred. The CART analysis showed 

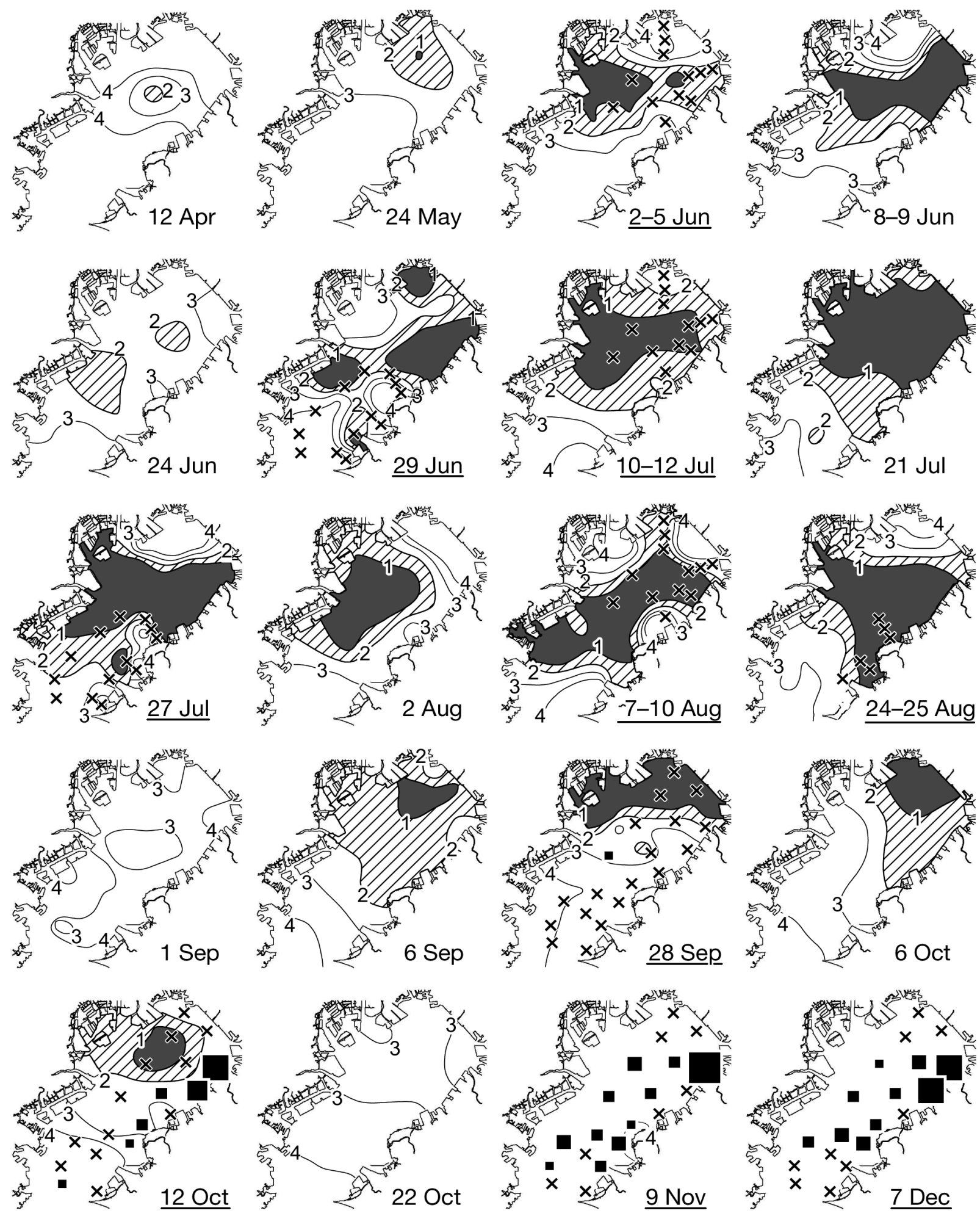

Juvenile abundance $\left(10^{-3}\right.$ ind $\left.\mathrm{m}^{-2}\right)$

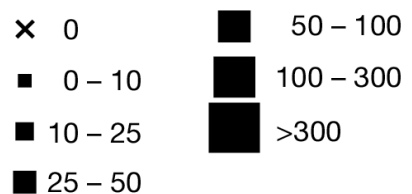

Fig. 3. Spatial distribution of bottom DO concentration in Tokyo Bay between April and December 2004. Lines: DO contours $\left(1 \mathrm{ml} \mathrm{l}^{-1}\right.$ intervals). Shaded area: DO concentration $\leq 1 \mathrm{ml} \mathrm{l}^{-1}$; hatched area: DO concentration $\leq 2 \mathrm{ml} \mathrm{l}^{-1}$. Spatial distribution of Oratosquilla oratoria juveniles overlaid (ם), and sampling trawl dates underlined 
that the threshold level of DO concentration for the existence of juveniles was $2.78 \mathrm{ml} \mathrm{l}^{-1}$ (Fig. 4).

To determine the effects of abiotic factors on the spatial distribution and settlement period, we performed GAM analyses for the period June to December, during which time juveniles were expected to occur, as indicated by data on the reproductive period of Oratosquilla oratoria in the bay (Hamano \& Matsuura 1987a, Kodama et al. 2004, 2006a). The optimum GAM model consisted of bottom DO concentration, latitude, and depth as linear functions, and longitude and sampling date as nonlinear smoothing functions $(\mathrm{AIC}=$ $6.12, \mathrm{R}^{2}=0.59$ ). Bottom DO concentration had a significant linear effect on juvenile occurrence, with increasing frequency of occurrence as bottom DO concentration increased $(F=5.4$, df $=1.0, \mathrm{p}<0.05$, Fig. 5). Depth had a linear effect on the frequency of juvenile occurrence, showing that juveniles had a preference for deeper areas $(F=35.5, \mathrm{df}=1.0, \mathrm{p}<0.01$, Fig. 5). Although juveniles occurred in the northern part of the bay (Fig. 3), the frequency of their occurrence decreased linearly with increasing latitude $(F=5.5$, df $=1.0, \mathrm{p}<0.05$, Fig. 5), suggesting that their distribution there is contracted because of the presence of bottom hypoxia (Fig. 3). Longitude had a nonlinear effect on the frequency of juvenile occurrence $(F=12.5$, $\mathrm{df}=3.0$, $\mathrm{p}<0.01$, Fig. 5). The probability that juveniles were present was high in the eastern part of the bay (Fig. 5), reflecting the finding that juveniles occurred continu-

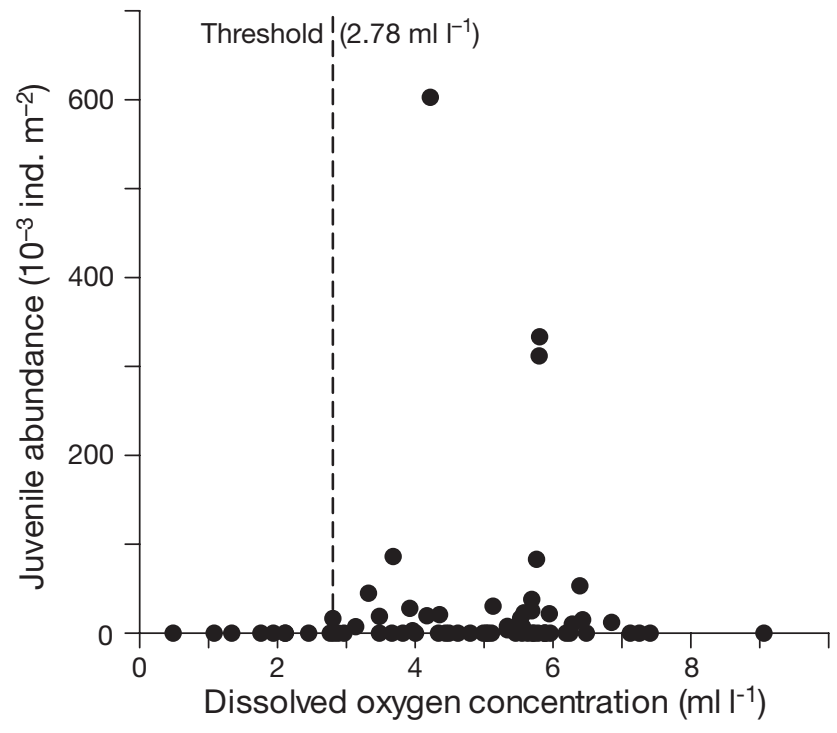

Fig. 4. Oratosquilla oratoria. Juvenile abundance against bottom DO concentration. Data on each station between September and December (during which juveniles occurred) is shown. Broken line: threshold bottom DO concentration for existence of juveniles, based on classification and regression tree (CART) analysis
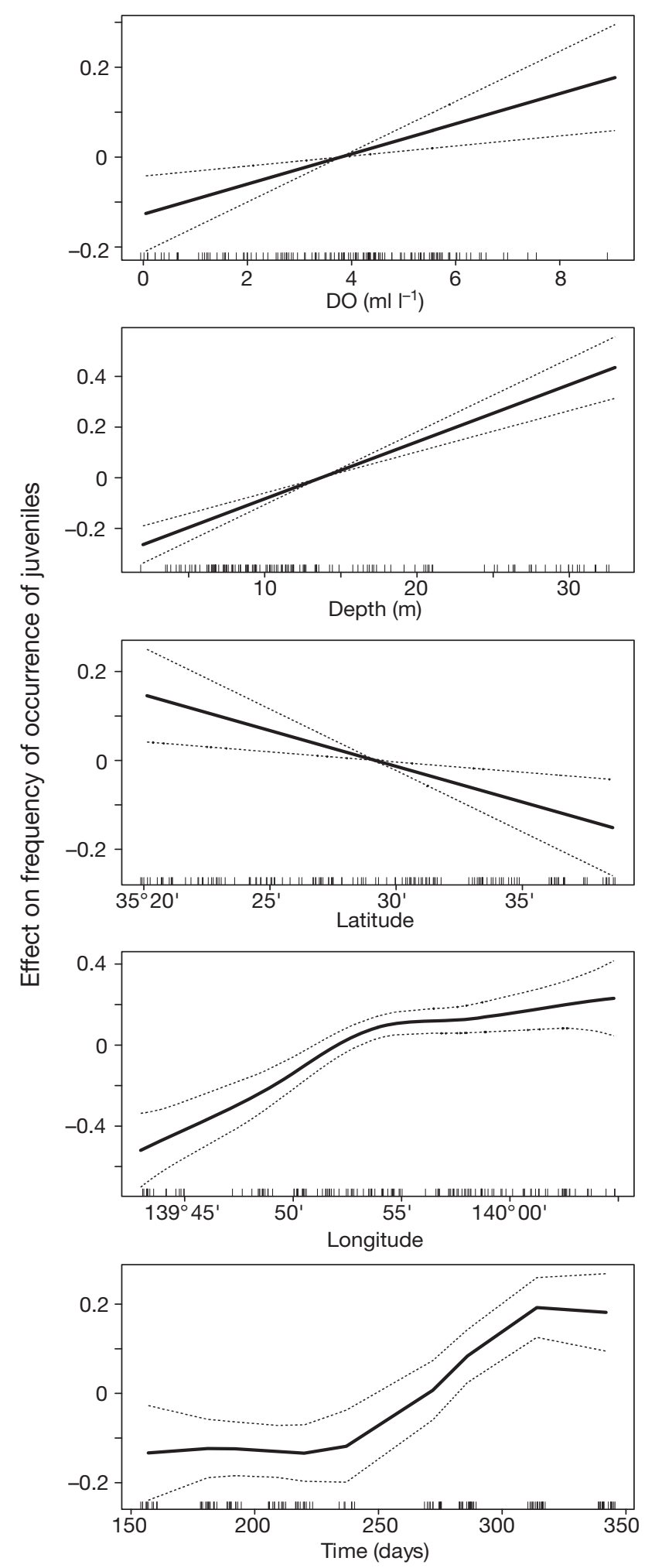

Fig. 5. Oratosquilla oratoria. Juvenile occurrence as predicted from the best fitting generalized additive model (GAM) by linear functions for bottom DO concentration, depth, and latitude; and by smoothing functions for longitude and time (number of days since 1 January). Broken lines: $2 \times \mathrm{SE}_{\text {; }}$ vertical lines on $x$-axis: sampling intensity 
ously in the eastern coastal regions during the peak settlement period and thereafter (October to December; Fig. 3). However, the results seemed contradictory between longitude and depth, because the water becomes increasingly shallow moving eastward across the bay (Fig. 1). This may reflect avoidance of bottom hypoxia by juveniles. Sampling date had a significant nonlinear effect on the frequency of juvenile occurrence $(F=53.2, \mathrm{df}=14.2, \mathrm{p}<0.01$, Fig. 5). The probability that juveniles were present increased with time and peaked in November and December (Fig. 5), suggesting that the spatial distribution of juveniles expanded from the shallow eastern coast to the deep south-central area of the bay after the hypoxia had disappeared, from November onward (Fig. 3).

\section{DISCUSSION}

\section{Hypoxia in Tokyo Bay}

In Tokyo Bay, hypoxic bottom water persisted from April to October and disappeared from November onward. Salinity stratification was nearly stable throughout the survey period; $\Delta S$ ranged from 1.3 to $3.9 \mathrm{psu}$, although it was extremely high in October. Temperature began to drop from September onward, and temperature stratification collapsed in October, an event that would have resulted in an abatement of the hypoxia in the bay; in the Neuse River Estuary, a decrease in water temperature suppressed the development of hypoxia at a constant salinity stratification level (Buzzelli et al. 2002).

Hypoxic bottom water fluctuated in spatial extent and distribution in Tokyo Bay; in part this was due to an influx of oceanic water from the outside of the bay (Fujiwara \& Yamada 2002). Freshwater input and wind cause estuary circulation and vertical mixing in Tokyo Bay (Tanaka et al. 1998), and these events may affect the spatial distribution of hypoxia in the bay, as has been observed in the Pearl River Estuary and the adjacent coastal waters (Yin et al. 2004). Hypoxia in the bay temporarily abated in late June and early September 2004. Occasional wind events, such as storms, cause vertical mixing and interrupt the development of hypoxia in bottom waters (Glasgow \& Burkholder 2000, Yin et al. 2004). Tropical cyclones, typhoons Dianmu (mid June) and Chaba (end of August), approached Tokyo Bay and caused strong winds (weather observation data from the website of the Japan Meteorological Agency, www.jma.go.jp/jma/ indexe.html); this probably resulted in vertical mixing of the water column and the supply of oxygensaturated water from the surface to the bottom layer of the bay.

\section{Effects of hypoxia on early life history}

Our results suggest that the spatial distribution of Oratosquilla oratoria juveniles in Tokyo Bay is restricted by the presence of hypoxic water, as observed in fishes and invertebrates in other aquatic systems (Pihl et al. 1991, Eby \& Crowder 2002, Craig \& Crowder 2005). CART analysis showed that the threshold DO level at sites where juveniles existed was $2.78 \mathrm{ml}$ $\mathrm{I}^{-1}$, suggesting that $O$. oratoria may die, or at least not live normally, at lower DO concentrations. Rearing experiments have shown that $O$. oratoria starts to become immobile at DO $<3.1 \mathrm{ml} \mathrm{l}^{-1}$ and die at $<0.6 \mathrm{ml}$ $\mathrm{l}^{-1}$ (Hamano \& Yamamoto 2005). Immobilization and death under hypoxic conditions also have been reported in the blue crab Callinectes sapidus (Tankersley \& Wieber 2000) and the lobster Nephrops norvegicus (Hagerman \& Uglow 1985).

High abundance of newly settled juveniles was found in October in the northeastern part of the bay, near the hypoxic edge. The juveniles expanded their spatial distribution from the shallow northeastern coastal area to the deep south-central area of the bay from November onward, coinciding with the abatement of hypoxic conditions. Habitat compression due to hypoxia may induce increased predation risk, decreased food availability, and decreased individual growth rate, resulting in decreased population size (Eby \& Crowder 2002, Craig \& Crowder 2005). The occurrence of these phenomena in the Oratosquilla oratoria population in Tokyo Bay should be assessed by further study.

It is unknown whether Oratosquilla oratoria voluntarily avoids hypoxic water and migrates toward normoxic habitats, as has been reported for fishes and invertebrates in other aquatic systems (Pihl et al. 1991, Breitburg 1992, Eby \& Crowder 2002, Craig \& Crowder 2005). Two possibilities that might cause juveniles to start migration to deep areas can be considered. First, $O$. oratoria might be able to detect favorable DO concentrations for survival and start migrating from the shallow coastal areas to the deep areas, where the hypoxic water has disappeared. Second, O. oratoria might not be able to detect lethal hypoxia but instead extends its distribution innately, for example, by foraging migration (Jennings et al. 2001), regardless of whether the DO concentration in an area is fatal. In the second case, only individuals that move to the normoxic area would survive. If the second explanation were true, mass mortality would occur if hypoxic water persisted after juveniles had begun their migration. In addition, juveniles remaining in the northern part of the bay would die out if they could not detect and escape from the hypoxic water formed the next year. Although the blue crab Callinectes sapidus can detect 
hypoxia, behavior indicating positive avoidance of hypoxic water does not occur, and some individuals will remain in severely hypoxic water (Das \& Stickle 1994, Bell et al. 2003). A study to reveal whether $O$. oratoria can detect and escape from hypoxia needs to be performed to help us understand the recruitment mechanisms of $O$. oratoria in Tokyo Bay.

We found juvenile Oratosquilla oratoria only from late September onward. The spawning season of O. oratoria in Tokyo Bay lasted from May to September, and the early spawning peak by large females $\geq 1$ yr old occurs in May (Kodama et al. 2004, 2006a). Larvae from the early spawning season start to occur from early June (Kodama et al. 2004, 2006a). However, newly settled juveniles were not found until late September, although the duration between spawning and settlement is 7 to $10 \mathrm{wk}$ (Hamano \& Matsuura 1987a). Our GAM analysis showed that sampling date, DO concentration, depth, latitude, and longitude had significant effects on the occurrence of $O$. oratoria juveniles, suggesting that hypoxia had adverse effects on the time and location of settlement. However, we can only speculate on the factors causing the absence or extremely low abundance of juveniles before September.

One possibility is that settlement by the earlyspawned larvae failed, largely because of the effects of hypoxia persisting in the settlement ground in the northern to eastern parts of the bay until October. However, failure of the settlement from the early spawning season could not be proved from our data: because Oratosquilla oratoria lacks indicators of aging equivalent to the otoliths used in fishes, it is impossible to estimate the hatching dates of settled juveniles. In Tokyo Bay, similar recruitment patterns have been observed in the dragonet Repomucenus valenciennei. Although $R$. valenciennei has 2 spawning peaks (spring and autumn), otolith analysis of settled juveniles suggests that individuals that hatch between April and August are not recruited, probably because of the effect of bottom hypoxia in the bay (Ikejima \& Shimizu 1999).

Other environmental and ecological factors may be responsible for the high mortality rate of the early cohort during the pelagic larval phase of Oratosquilla oratoria, thus resulting in the extremely low juvenile abundance before September.

First, contraction of the vertical distribution of larvae due to effect of hypoxia may induce mass mortality during the pelagic phase. Larvae of O. oratoria show a distinct diurnal vertical migration: larvae occur exclusively near the sea surface at night, whereas their vertical distribution is dispersed from the sea bottom to the intermediate layer of the water column during the day (Senta 1967, Nakata 1986, 1987). However, when hypoxic bottom water is present the vertical distribution is restricted to the surface layer, even in the daytime (Nakata 1986). The proportion of the hypoxic area in Tokyo Bay was especially high from July to August (Fig. 2), during which time larvae from the early spawning season occurred (Kodama et al. 2004, 2006a). Contraction of the vertical distribution of the larvae within the surface layer as a result of hypoxia may induce higher risks of predation and increased competition for prey, thereby resulting in high mortality of the early-spawned larvae.

Hypoxic conditions have been shown to induce increased rates of predator-prey interaction. Predation by jellyfishes (which are tolerant to low DO concentrations) on fish larvae increases in oxygen-depleted situations owing to a reduction in the larvae's ability to escape (Breitburg et al. 1997, Shoji et al. 2005). In Tokyo Bay, the scyphozoan medusa Aurelia aurita is an abundant jellyfish that occurs throughout the year and forms dense aggregations (Nomura \& Ishimaru 1998). A. aurita selects large prey with slow escape speeds, rather than the more abundant copepods and microzooplankton (Sullivan et al. 1994). Increased predation by $A$. aurita on Oratosqilla oratoria larvae may occur, if the escape ability of $O$. oratoria larvae decreases under hypoxic conditions and the spatial distributions of dense patches of both species overlap during times of bottom hypoxia. This possibility needs to be examined by further study.

Second, delayed metamorphosis into juveniles of larvae at the final developmental stage was observed in Oratosqilla oratoria in Yuya Bay, which was considered to be a successful adaptation to avoid substrate inappropriate for settlement and thus increase survival rates by prolonging the pelagic phase (Hamano \& Matsuura 1987b, Hamano 2005). In Tokyo Bay, newly settled juveniles occurring in September or October could be derived from the early spawning season if the early-spawned larvae were to prolong the pelagic phase in response to bottom hypoxia. Prolongation of the larval phase may increase the predation risk, as observed in larvae of the capelin Mallotus villosus: older and larger larvae experience higher mortality rates (Litvak \& Leggett 1992). The occurrence of delayed metamorphosis as well as the size-dependent mortality of $O$. oratoria larvae in Tokyo Bay should be examined further.

In addition, other factors, such as low prey availability and/or advection of larvae out of the bay by unfavorable currents (Nakata 1986), could induce mass mortality of early-spawned larvae, resulting in the observed low juvenile abundance before September.

In conclusion, our results suggest that hypoxia is directly and/or indirectly associated with mass-mortality events during early life history. However, the va- 
lidity of the above-mentioned hypotheses, probably induced by bottom hypoxia, remains unconfirmed and needs to be revealed by further investigations of the causal link between hypoxia and $O$. oratoria recruitment.

Acknowledgements. We thank the fishermen of Chiba and Kanagawa Prefectures for their help with field sampling. Thanks also to A. Goto, R. Yamada, S. Ochiai, H. Tanaka, T. Fujino, and T. Kaneko for help with field sampling. We also thank 4 anonymous reviewers for their valuable scientific comments on this manuscript. This study was funded in part by the Sasakawa Scientific Research Grant (16-403M).

\section{LITERATURE CITED}

Akaike H (1973) Information theory and an extension of the maximum likelihood principle. In: Petrov BN, Csáki F (eds) Second international symposium on information theory. Akadémial Kiadó, Budapest, p 267-281

Baden SP, Loo LO, Pihl L, Rosenberg R (1990) Effects of eutrophication on benthic communities including fish: Swedish West Coast. Ambio 19:113-122

Bell GW, Eggleston DB, Wolcott TG (2003) Behavioral responses of free-ranging blue crabs to episodic hypoxia. I. Movement. Mar Ecol Prog Ser 259:215-225

Breitburg DL (1992) Episodic hypoxia in Chesapeake Bay: interacting effects of recruitment, behavior, and physical disturbance. Ecol Monogr 62:525-546

Breitburg DL, Steinberg N, Dubeau S, Cooksey C, Houde ED (1994) Effects of low dissolved-oxygen on predation on estuarine fish larvae. Mar Ecol Prog Ser 104:235-246

Breitburg DL, Loher T, Pacey CA, Gerstein A (1997) Varying effects of low dissolved oxygen on trophic interactions in an estuarine food web. Ecol Monogr 67:489-507

Buzzelli CP, Luettich RA, Powers SP, Peterson CH, McNinch JE, Pinckney JL, Paerl HW (2002) Estimating the spatial extent of bottom-water hypoxia and habitat degradation in a shallow estuary. Mar Ecol Prog Ser 230:103-112

Clark LA, Pregibon D. (1992) Tree-based models. In: Chambers JM, Hastie TJ (eds) Statistical models in S. Chapman \& Hall, New York, p 377-419

Craig JK, Crowder LB (2005) Hypoxia-induced habitat shifts and energetic consequences in Atlantic croaker and brown shrimp on the Gulf of Mexico shelf. Mar Ecol Prog Ser 294:79-94

Das T, Stickle WB (1994) Detection and avoidance of hypoxic water by juvenile Callinectes sapidus and C. similis. Mar Biol 120:593-600

Diaz RJ, Rosenberg R (1995) Marine benthic hypoxia: a review of its ecological effects and the behavioral responses of benthic macrofauna. Oceanogr Mar Biol Annu Rev 33:245-303

Eby LA, Crowder LB (2002) Hypoxia-based compression in the Neuse River Estuary: context-dependent shifts in behavioral avoidance thresholds. Can J Fish Aquat Sci 59: 952-965

Eby LA, Crowder LB, McClellan CM, Peterson CH, Powers MJ (2005) Habitat degradation from intermittent hypoxia: impacts on demersal fishes. Mar Ecol Prog Ser 291: $249-261$

Fujiwara T, Yamada Y (2002) Inflow of oceanic water into Tokyo Bay and generation of a subsurface hypoxic water mass. J Geophys Res 107(C5):3045 doi:10.1029/ 2000JC000749
Glasgow HB, Burkholder JM (2000) Water quality trends and management implications from a five-year study of a eutrophic estuary. Ecol Appl 10:1024-1046

Hagerman L, Uglow RF (1985) Effects of hypoxia on the respiratory and circulatory regulation of Nephrops norvegicus. Mar Biol 57:273-278

Hamano T (2005) Biology of stomatopod crustaceans and stock management of the Japanese mantis shrimp Oratosquilla oratoria. Japan Fisheries Resource Conservation Association, Tokyo (in Japanese)

Hamano T, Matsuura S (1984) Egg laying and egg mass nursing behavior in the Japanese mantis shrimp. Nippon Suisan Gakkaishi 50:1969-1973

Hamano T, Matsuura S (1987a) Egg size, duration of incubation, and larval development of the Japanese mantis shrimp in the laboratory. Nippon Suisan Gakkaishi 53: 23-39

Hamano T, Matsuura S (1987b) Delayed metamorphosis of the Japanese mantis shrimp in nature. Nippon Suisan Gakkaishi 53:167

Hamano T, Yamamoto K (2005) Rheotaxis and tolerance to oxygen deficiency as factors affecting the spatial pattern and the stock of the Japanese mantis shrimp Oratosquilla oratoria in fishing grounds. J Natl Fish Univ 53:117-129 (in Japanese with English abstract)

Hastie TJ (1992) Generalized additive models. In: Chambers JM, Hastie TJ (eds) Statistical models in S. Chapman \& Hall, New York, p 249-308

Hastie TJ, Tibshirani RJ (1990) Generalized additive models. Chapman \& Hall, London

Ikejima K, Shimizu M (1999) Disappearance of a spring cohort in a population of the dragonet, Repomucenus valenciennei, with spring and autumn spawning peaks in Tokyo Bay, Japan. Ichthyol Res 46:331-339

Jennings S, Kaiser MJ, Reynolds JD (2001) Marine fisheries ecology. Blackwell Science, Oxford

Kodama K, Aoki I, Taniuchi T, Shimizu M (2002) Long-term changes in the assemblage of demersal fishes and invertebrates in relation to environmental variations in Tokyo Bay, Japan. Fish Manage Ecol 9:303-313

Kodama K, Aoki I, Shimizu T (2003) Possible factors causing the fluctuation of the recruitment of Japanese mantis shrimp Oratosquilla oratoria in Tokyo Bay. Bull Kanagawa Pref Fish Res Inst 8:71-76 (in Japanese with English abstract)

Kodama K, Shimizu T, Yamakawa T, Aoki I (2004) Reproductive biology of the female Japanese mantis shrimp Oratosquilla oratoria (Stomatopoda) in relation to changes in the seasonal pattern of larval occurrence in Tokyo Bay, Japan. Fish Sci 70:734-745

Kodama K, Yamakawa T, Shimizu T, Aoki I (2005) Age estimation of the wild population of Japanese mantis shrimp Oratosquilla oratoria (Crustacea: Stomatopoda) in Tokyo Bay, Japan, using lipofuscin as an age marker. Fish Sci 71 : $141-150$

Kodama K, Shimizu T, Yamakawa T, Aoki I (2006a) Changes in reproductive patterns in relation to decline in stock abundance of the Japanese mantis shrimp, Oratosquilla oratoria, in Tokyo Bay. Fish Sci 72:568-577

Kodama K, Kume G, Shiraishi H, Morita M, Horiguchi T (2006b) Relationship between body length and processedmeat length and seasonal change in net processed-meat yield of Japanese mantis shrimp (Oratosquilla oratoria) in Tokyo Bay. Fish Sci 72:804-810

Kodama K, Shiraishi H, Morita M, Horiguchi T (2006c) Verification of lipofuscin-based crustacean ageing: seasonality of lipofuscin accumulation in the stomatopod Oratosquilla 
oratoria in relation to water temperature. Mar Biol 150:131-140

Litvak MK, Leggett WC (1992) Age and size-selective predation on larval fishes: the bigger-is-better hypothesis revisited. Mar Ecol Prog Ser 81:13-24

Nakata N (1986) Larval distribution of Oratosquilla oratoria (de Haan) in Tokyo Bay. Bull Kanagawa Pref Exp Stn 7: 17-22 (in Japanese)

Nakata N (1987) Survey of the larvae of Oratosquilla oratoria using plankton net. In: Anonymous (ed) Report of an assessment of the effect of construction of an expressway across Tokyo Bay on the fishery. Japan Fisheries Resource Conservation Association, Tokyo, p 279-283 (in Japanese)

Nomura H, Ishimaru T (1998) Monitoring the occurrence of medusae and ctenophores in Tokyo Bay, central Japan, in recent 15 years. Umi no Kenkyu 7:99-104 (in Japanese with English abstract)

Ohtomi J, Shimizu M (1991) The spawning ground of the Japanese mantis shrimp Oratosquilla oratoria in Tokyo Bay, Japan. Nippon Suisan Gakkaishi 57:447-451

Pihl L, Baden SP, Diaz RJ (1991) Effects of periodic hypoxia on distribution of demersal fish and crustaceans. Mar Biol 108:349-360

Senta T (1967) Seasonal abundance and diurnal migration of alima larva of Squilla oratoria in the Seto Inland Sea. Nip-

Editorial responsibility: Howard Browman (Associate Editorin-Chief), Storebø, Norway pon Suisan Gakkaishi 33:508-512 (in Japanese with English abstract)

Shoji J, Masuda R, Yamashita Y, Tanaka M (2005) Predation on fish larvae by moon jellyfish Aurelia aurita under low dissolved oxygen concentrations. Fish Sci 71:748-753

Sullivan BK, Garcia JR, Klein-MacPhee G (1994) Prey selection by the scyphomedusan predator Aurelia aurita. Mar Biol 121:335-341

Swartzman G, Huang CH, Kaluzny S (1992) Spatial analysis of Bering Sea groundfish survey data using generalized additive models. Can J Fish Aquat Sci 49:1366-1378

Tanaka M, Inagaki S, Stelling GS (1998) Numerical simulation of flow under the stratified condition in Tokyo Bay, Japan. In: Babovic V, Larsen LC (eds) Hydroinformatics 98. Balkema, Rotterdam, p 1463-1468

Tankersley RA, Wieber MG (2000) Physiological responses of postlarval and juvenile blue crabs Callinectes sapidus to hypoxia and anoxia. Mar Ecol Prog Ser 194: 179-191

Wu RSS, Zhou BS, Randall DJ, Woo NYS, Lam PKS (2003) Aquatic hypoxia is an endocrine disruptor and impairs fish reproduction. Environ Sci Technol 37:1137-1141

Yin K, Lin Z, Ke Z (2004) Temporal and spatial distribution of dissolved oxygen in the Pearl River Estuary and adjacent coastal waters. Cont Shelf Res 24:1935-1948

Submitted: April 19, 2005; Accepted: April 14, 2006 Proofs received from author(s): September 22, 2006 